\title{
Cronobacter spp.: infecções, ocorrência e regulação em alimentos - uma revisão no Brasil
}

\author{
Cronobacter spp.: infections, occurrence and food regulations - a review in Brazil
}

\author{
Marcelo Luiz Lima Brandão1*, Natália Scudeller Umeda', Ivano de Filippis' \\ 1 Instituto Nacional de Controle de Qualidade em Saúde, Departamento de Microbiologia, Rio de Janeiro/RJ - Brasil
}

\begin{abstract}
${ }^{*}$ Corresponding Author
Marcelo Luiz Lima Brandão, Instituto Nacional de Controle de Qualidade em Saúde, Departamento de Microbiologia, Av. Brasil, 4365, Manguinhos, CEP: 21040-900, Rio de Janeiro/RJ - Brasil, e-mail: marcelollib8@gmail.com
\end{abstract}

Cite as: Cronobacter spp.: infections, occurrence and food regulations - a review in Brazil. Braz. J. Food Technol., v. 21, e2017074, 2018

Received: May 19, 2017; Accepted: Sept. 22, 2017

\section{Resumo}

Cronobacter é uma bactéria oportunista, associada a infecções em neonatos devido ao consumo de fórmulas infantis desidratadas. Atualmente, sabe-se que Cronobacter pode causar infecções em indivíduos de qualquer idade, sendo, em idosos, a sua maior prevalência, e a infecção urinária, a síndrome mais comum neste grupo. A identificação de fórmulas infantis desidratadas como veículo de contaminação em casos de meningite causada por Cronobacter em neonatos levou as agências de regulação a criarem medidas específicas para o controle destes patógenos nestes produtos. Uma revisão bibliográfica foi realizada sobre a epidemiologia das infecções por Cronobacter, a ocorrência do patógeno e a regulação na área de alimentos no Brasil. Constatou-se que casos de infecções foram reportados no país no período de 1997-2013, com maior ocorrência em neonatos. O número preciso de casos não pôde ser determinado e, em alguns dos relatos, a identificação fidedigna dos micro-organismos pode ser questionável. Na maioria dos casos relatados o veículo de contaminação não foi investigado ou não pôde ser determinado. Já ocorreram relatos da contaminação de amostras de fórmulas infantis desidratadas comercializadas no Brasil por Cronobacter, mas sua ocorrência parece ter sido reduzida após a adoção de medidas sanitárias mais rígidas pelos órgãos reguladores. Cronobacter também foi isolada de temperos e condimentos, farinhas, queijo e misturas de cereais para crianças; destas amostras, quatro espécies foram identificadas: C. sakazakii, C. malonaticus, $C$. dublinensis e $C$. muytjensii. A presença do patógeno em diferentes classes de alimentos é preocupante pois pode representar um risco caso sejam consumidos por indivíduos pertencentes a algum grupo de risco (neonatos e idosos). O incentivo à realização de pesquisas sobre a epidemiologia do gênero Cronobacter é importante para identificar as classes de alimentos que podem atuar como veículo de contaminação e a real prevalência das infecções no Brasil.

Palavras-chave: Cronobacter; Infecções; Segurança de alimentos; Controle da qualidade; Regulação.

\section{Abstract}

Cronobacter is an opportunistic bacterium associated with infections in newborns due to the consumption of powdered infant formulae. It is now known that Cronobacter can cause infections in individuals of any age with a higher prevalence in the elderly, urinary infections being the most common syndrome in this group. The identification of powdered infant formulae as the contamination vehicle in cases of meningitis caused by Cronobacter in neonates led the regulatory agencies to establish specific measures to control such pathogens in these products. Thus a literature review was carried out concerning the epidemiology of Cronobacter infections, the occurrence of the pathogen and food regulations in Brazil. It was found that cases of the infection were reported in Brazil from 1997-2013, with a higher occurrence in neonates. The precise number of cases could not be determined, and in some reports, identification of the microorganism was questionable. In most of the cases reported the contamination vehicle was not investigated or could not be determined. There have been reports of contamination by Cronobacter in samples of powdered infant formulae commercialized in Brazil, but their occurrence seems to have reduced after the adoption of stricter sanitary measures by the regulatory agencies. Cronobacter has also been isolated from spices and herbs, flours, cheese and from cereal mixes destined for children; and from these samples, four species were identified: C. sakazakii, C. malonaticus, C. dublinensis and C. muytjensii. The presence of the pathogen 
in different types of food is worrying because it may represent a risk if consumed by individuals belonging to one of the risk groups (neonates and elderly). It is important to encourage research about the epidemiology of the genus Cronobacter in order to identify the classes of food that can act as contamination vehicles and the real prevalence of infections in Brazil.

Keywords: Cronobacter; Infections; Food safety; Quality control; Regulation.

\section{Introdução}

O gênero Cronobacter foi inicialmente classificado como Enterobacter cloacae produtor de pigmento amarelo e, posteriormente, reclassificado como uma nova espécie denominada na época Enterobacter sakazakii (FARMER 3rd et al., 1980). Em 2007, uma extensa análise polifásica foi realizada utilizando-se estirpes de E. sakazakii e de outras espécies relacionadas. As cepas de E. sakazakii foram separadas em grupos a partir de perfis obtidos por amplificação de fragmentos polimórficos fluorescentes de ácido desoxirribonucleico (DNA), perfis de ribotipagem, análise de sequências gênicas completas de $16 \mathrm{~S}$ rRNA e hibridização DNA-DNA. Assim, foi proposta a reclassificação do micro-organismo E. sakazakii, dentro da família Enterobacteriaceae, como um novo gênero, Cronobacter spp., com quatro espécies, duas subespécies e uma genomoespécie, conforme relacionado a seguir: Cronobacter sakazakii subsp. sakazakii, Cronobacter sakazakii subsp. malonaticus, Cronobacter muytjensii, Cronobacter dublinensis, Cronobacter turicensis e Cronobacter genomoespecies 1 (IVERSEN et al., 2007a). Em 2008, um novo estudo polifásico foi realizado por Iversen et al. (2008), empregando-se as provas bioquímicas de utilização do malonato, produção de indol, os sistemas Biotype 100 (bioMérieux) e Biolog Phenotype MicroArray data (Biolog), e novos experimentos de hibridização DNA-DNA. Uma nova classificação foi proposta, compreendendo cinco espécies e uma genomoespécie: C. sakazakii, C. malonaticus, C. turicensis, C. muytjensii, C. dublinensis e $C$. genomoespecies 1 ; e três subespécies, $C$. dublinensis subsp. dublinensis, $C$. dublinensis subsp. lausannensis e C. dublinensis subsp. lactaridi. Em 2012, uma reavaliação da classificação taxonômica foi realizada utilizando-se uma análise polifásica, incluindo caracterização fenotípica, análise de sequências gênicas completas de 16S rRNA, Multilocus sequence analysis (MLSA) e hibridização DNA-DNA. Foi observado que uma cepa previamente caracterizada como C. sakazakii formava uma linhagem filogenética independente e a hibridização DNA-DNA determinou sua identidade como uma nova espécie, denominada Cronobacter condimenti (JOSEPH et al., 2012). Em adição, utilizando-se a técnica de MLSA, foi observado que as duas cepas de $C$. genomoespecies $1 \mathrm{e}$ as outras duas de $C$. turicensis apresentavam-se no mesmo grupo, formando uma linhagem filogenética independente. Os dados da hibridização DNA-DNA e a caracterização fenotípica confirmaram que estas estirpes representavam uma única espécie, que foi denominada Cronobacter universalis. Desta forma, o gênero Cronobacter é composto, atualmente, por sete espécies: $C$. sakazakii, C. malonaticus, C. dublinensis, C. turicensis, C. muytjensii, C. universalis e C. condimenti (IVERSEN et al., 2008; JOSEPH et al., 2012).

As infecções por Cronobacter podem ocorrer em todas as faixas etárias e a literatura apresenta relatos de surtos e casos isolados de infecções em diversos países (FAO, 2008). Já existem relatos de casos em crianças de primeira infância (>6 meses) (BOWEN; BRADEN, 2006; RAY et al., 2007) e em adultos (SANTOS et al., 2000; LAI, 2001; BHAT et al., 2009; TSAl et al., 2013). As principais síndromes clínicas das infecções são a bacteremia, septicemia e a meningite (LAI, 2001; BOWEN; BRADEN, 2006). Os casos de meningite foram reportados somente em neonatos e, em muitos casos, o veículo de contaminação foram fórmulas infantis desidratadas (FID) contaminadas pelo patógeno (JASON, 2012). Cronobacter tem sido isolada de uma grande variedade de outras infecções, como enterocolite necrosante (LAI 2001), infecções pulmonares (SEE et al., 2007), infecções urinárias (BHAT et al., 2009; PATRICK et al., 2014) e colecistite aguda (TSAl et al., 2013). Contudo, na grande maioria destes casos, não foi comprovado que o Cronobacter era efetivamente o responsável pela infecção, uma vez que outros micro-organismos também foram identificados no sítio da infecção (FARMER 3rd, 2015).

A maioria dos casos de infecções descritos na literatura é proveniente de países desenvolvidos, enquanto que a situação parece ser radicalmente diferente nos demais países (BOWEN; BRADEN, 2006; FRIEDEMANN, 2009). Essa ambiguidade pode ser atribuída às diferenças socioculturais nas práticas de alimentação infantil, uma vez que o uso de FID na alimentação de neonatos é menos frequente em países em desenvolvimento (RAY et al., 2007). Além disso, muitos países não possuem um sistema de vigilância para notificação dos casos de infecções por Cronobacter spp., o que leva a uma subestimação da sua real prevalência (STRYDOM et al., 2012). Para Famer 3rd (2015), as agências governamentais deveriam tornar as infecções por Cronobacter uma doença de notificação obrigatória, como é o caso de muitas outras doenças infecciosas sérias.

Outra questão é que muitos laboratórios clínicos, independentemente do país, não realizam técnicas de 
Cronobacter spp.: infecções, ocorrência e regulação em alimentos - uma revisão no Brasil

Brandão, M. L. L. et al.

identificação de Cronobacter na sua rotina. Além disso, já é sabido que determinados métodos fenotípicos comumente utilizados em laboratórios clínicos, como, por exemplo, o kit miniaturizado API 20E ou o sistema semiautomatizado Vitek 2.0, não são confiáveis para correta identificação do gênero Cronobacter (IVERSEN et al., 2007b; WARNKEN et al., 2012; JOSEPH et al., 2013).

Atualmente, os métodos moleculares, principalmente o sequenciamento do gene fusA, que é um dos sete genes sequenciados na técnica do Multi Locus Sequence Typing (MLST), são consideradas metodologias confiáveis para identificação fidedigna das espécies do gênero (FORSYTHE et al., 2014).

Considerando-se a ocorrência de casos de infecções por Cronobacter no Brasil e a importância para a Saúde Pública, na criação de medidas para o controle destes patógenos em alimentos, esta revisão tem como objetivo contribuir para a disseminação do conhecimento sobre estes patógenos emergentes de origem alimentar no país.

\section{Material e métodos}

Um extenso levantamento de artigos científicos, relatórios, resumos de congressos e documentos legislativos que tratam do tema foi realizado, considerando-se as bases de dados textuais e referências disponíveis na internet. A estratégia de busca contou com artigos indexados na base de dados PubMed e periódicos CAPES, além de consultas aos sítios eletrônicos da Agência Nacional de
Vigilância Sanitária (Anvisa), do Ministério da Saúde, do Codex Alimentarius, entre outros, que serviram de base para o desenvolvimento deste trabalho. Os descritores utilizados na busca foram: "Cronobacter", "Cronobacter sakazakii", "C. sakazakii", "Enterobacter sakazakii", "E. sakazakii" e "yellow-pigmented Enterobacter cloacae", conforme recomendado por Farmer 3rd (2015), para buscas na literatura sobre este tema. Realizado o levantamento bibliográfico, os trabalhos foram separados e os dados organizados para descrição dos resultados.

\section{Resultados e discussão}

\subsection{Surtos e casos de infecções por Cronobacter spp. no Brasil}

No Brasil, casos de infecções por Cronobacter spp. em neonatos, crianças e adultos já foram reportados (OLIVEIRA et al., 1999; SANTOS et al., 2000; BARREIRA et al., 2003; BRANDAO et al., 2015) e se encontram listados na Tabela 1. Contudo, este número é provavelmente subestimado. Uma das causas disso é porque as infecções causadas por Cronobacter não estão incluídas na lista nacional de notificação compulsória de doenças, agravos e eventos de

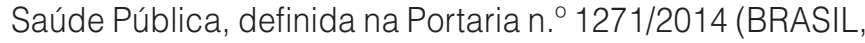
2014c). Os dados disponibilizados pelo Ministério da Saúde relativos aos surtos de doenças transmitidas por alimentos ocorridos no Brasil no período de 2000 a 2014 não especificam nenhum caso cujo agente etiológico tenha sido Cronobacter spp. ou Enterobacter sakazakii.

Tabela 1. Relatos de infecções por Cronobacter spp./Enterobacter sakazakii ocorridas no Brasil, no período 1997-2013.

\begin{tabular}{|c|c|c|c|c|c|c|c|c|}
\hline Referência & Estado & $\begin{array}{l}\text { Idade/ } \\
\text { gênero }\end{array}$ & $\begin{array}{c}\text { Sítio de } \\
\text { isolamento }\end{array}$ & $\begin{array}{c}\text { Método de } \\
\text { identificação }\end{array}$ & $\begin{array}{c}\text { Apresentação } \\
\text { clínica }\end{array}$ & $\begin{array}{c}\text { Micro- } \\
\text { organismo } \\
\text { identificado }\end{array}$ & Tratamento & Desfecho \\
\hline $\begin{array}{l}\text { Oliveira et al. } \\
\text { (1999) }\end{array}$ & $\begin{array}{l}\text { Minas } \\
\text { Gerais }\end{array}$ & $\begin{array}{c}\text { Recém-nascidos } \\
\text { de alto risco }\end{array}$ & $N D^{a}$ & ND & ND & E. sakazakii & ND & ND \\
\hline \multirow{2}{*}{$\begin{array}{l}\text { Santos et al. } \\
\qquad(2000)\end{array}$} & \multirow{2}{*}{$\begin{array}{l}\text { Rio de } \\
\text { Janeiro }\end{array}$} & Dois adultos/ND & Hemocultura & $\begin{array}{c}\text { Testes } \\
\text { bioquímicos } \\
\text { e sistema } \\
\text { Vitek }\end{array}$ & Septicemia & E. sakazakii & Não realizado & Óbito \\
\hline & & $\begin{array}{c}\text { Uma criança e } \\
\text { dois neonatos/ND }\end{array}$ & Hemocultura & $\begin{array}{c}\text { Testes } \\
\text { bioquímicos } \\
\text { e sistema } \\
\text { Vitek }\end{array}$ & Septicemia & E. sakazakii & $\begin{array}{c}\text { Cefalosporina } \\
\text { de terceira } \\
\text { geração }\end{array}$ & Sobrevivência \\
\hline $\begin{array}{l}\text { Barreira et al. } \\
\qquad(2003)\end{array}$ & $\begin{array}{l}\text { São } \\
\text { Paulo }\end{array}$ & $\begin{array}{l}14 \text { dias/ } \\
\text { Feminino }\end{array}$ & Líquor & ND & Meningite & E. sakazakii & $\begin{array}{c}\text { Cefotriaxona } \\
+ \text { ampicilina } \\
\text { / Trocado por } \\
\text { Cefotaxima + } \\
\text { gentamicina }\end{array}$ & Óbito \\
\hline $\begin{array}{l}\text { Brandao et al. } \\
\qquad(2015)\end{array}$ & Piauí & $\begin{array}{l}\text { Três neonatos/ } \\
\text { Feminino }\end{array}$ & Hemocultura & $\begin{array}{c}\text { Biogrupos, } \\
\text { Vitek 2.0, } \\
\text { PCR }^{\mathrm{b}} \text { gluA, } \\
\text { PCR rpoB, } \\
\text { PFGE }\end{array}$ & Bacteremia & $\begin{array}{l}\text { Cronobacter } \\
\text { malonaticus }\end{array}$ & ND & ND \\
\hline
\end{tabular}

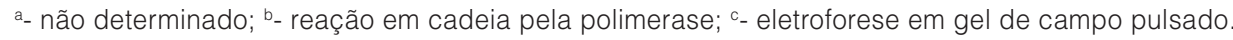


Existe apenas a descrição de seis surtos causados por Enterobacter spp., mas esta não especifica que alimentos foram identificados como veículo e a espécie do gênero que foi a responsável (BRASIL, 2014d). Outra questão é que a identificação correta destes microrganismos, nos serviços de assistência à saúde, é dificultada pela ausência de métodos adequados disponíveis nestes serviços ou pela falta de conhecimento dos profissionais de saúde sobre o patógeno (WARNKEN et al., 2012). Warnken et al. (2012) estudaram cepas de origem clínica, previamente identificadas como "E. sakazakil", por laboratórios clínicos no Brasil. Após a realização de técnicas moleculares mais robustas (PCR e PCR em tempo real, com alvo em genes específicos para o gênero), foi evidenciado que as cepas, na verdade, pertenciam a outras espécies da família Enterobacteriaceae com fenótipos parecidos com os do gênero Cronobacter, o que levou à identificação errônea.

O primeiro relato de um surto de infecção por Cronobacter, no Brasil, ocorreu em 1997 entre os recém-nascidos de alto risco da Unidade de Neonatologia do Hospital de Clínicas da Universidade Federal de Minas Gerais (OLIVEIRA et al., 1999). Neste episódio, não houve uma investigação para determinar o veículo de contaminação destes pacientes. Contudo, vale ressaltar que os autores não especificaram que métodos utilizaram para identificar o micro-organismo e, baseando-se nos conhecimentos atuais, sabe-se que muitas das técnicas comumente utilizadas em laboratórios clínicos podem levar a resultados falso-positivos (IVERSEN et al., 2007b; WARNKEN et al., 2012; JOSEPH et al., 2013).

Em 1998, sete episódios de septicemia causados por Cronobacter foram identificados em quatro hospitais privados no Estado do Rio de Janeiro: dois em uma Unidade de Terapia Intensiva (UTI) para adultos, um em uma UTI pediátrica e quatro em uma UTI neonatal (SANTOS et al., 2000). O patógeno foi isolado do sangue periférico e identificado por provas bioquímicas (não especificadas) e pela versão do sistema Vitek disponível na época. O veículo de contaminação identificado foi a solução de nutrição parenteral para crianças e neonatos, e a solução de lactato ringer contendo $5 \%$ de albumina para os adultos, uma vez que Cronobacter foi identificado em bolsas fechadas destas duas soluções. Contudo, novamente a questão dos métodos utilizados na identificação das bactérias pode levar à dúvida se estes micro-organismos realmente pertencem ao gênero Cronobacter. Atualmente, sabe-se que o sistema Vitek que foi utilizado na época do estudo pode levar a resultados falso-positivos (IVERSEN et al., 2007b; WARNKEN et al., 2012).

Em 2003, Barreira et al. (2003) relataram um caso de infecção por Cronobacter em uma menina de 14 dias de vida no Hospital Universitário da Universidade de São Paulo. A paciente apresentou quadro de meningite e evoluiu para choque séptico e posterior óbito, sendo o patógeno isolado a partir de uma amostra de líquor. O tratamento empírico inicial com ceftriaxona associada à gentamicina não foi eficaz e, após o resultado do antibiograma, foi alterado para cefotaxima associada à gentamicina. Este também não foi eficaz e a paciente acabou evoluindo para óbito. Os autores não descreveram que método(s) utilizaram para identificação do micro-organismo.

Os casos mais atuais ocorreram em 2013, em um surto, em um Hospital Maternidade na cidade de Teresina, Piauí. Neste episódio, três pacientes foram identificadas com bacteremia por Cronobacter spp. A investigação epidemiológica identificou a espécie $C$. malonaticus como a responsável pela infecção nas pacientes, porém não foi possível identificar a fonte de contaminação, uma vez que o patógeno não foi isolado nas amostras de alimentos suspeitos, que foram ingeridos pelas pacientes (BRANDAO et al., 2015).

\subsection{Ocorrência de Cronobacter spp. em alimentos, no Brasil}

Dados relativos à pesquisa de Cronobacter em alimentos no Brasil ainda são limitados. Os trabalhos identificados pesquisaram o patógeno em amostras de FID, temperos e condimentos, produtos farináceos, alimentos destinados a crianças de primeira infância, queijos e leite UHT, conforme apresentado na Tabela 2.

Em determinados trabalhos listados na Tabela 2, não foi realizada a identificação das espécies das cepas de Cronobacter isoladas. Nos trabalhos que realizaram esta identificação, Meier et al. (2016) isolaram 11 cepas de Cronobacter de alimentos infantis, sendo oito identificadas como C. sakazakii, duas como C. malonaticus e uma como C. dublinensis. Brandao et al. (2016) reportaram que o isolado da amostra de queijo Minas Frescal pertencia à espécie C. sakazakii. Brandao et al. (2017) isolaram 45 cepas, sendo 37 identificadas como C. sakazakii, três como C. malonaticus, três como $C$. dublinensis e duas como $C$. muytjensii. Os autores também avaliaram as cepas pela técnica do MLST e identificaram duas cepas pertencentes ao ST4, que é uma linhagem clonal bem definida, epidemiologicamente relacionada a casos graves de infecções em neonatos (JOSEPH; FORSYTHE, 2011; HARIRI et al., 2013).

Quanto ao isolamento de Cronobacter em amostras de outras fontes, Palcich et al. (2009) detectaram a bactéria no resíduo de uma mamadeira e em uma esponja utilizada para lavagem de mamadeiras provenientes de dois Hospitais Maternidade do Estado de São Paulo. Oliveira et al. (2011) detectaram Cronobacter em três amostras de enxágue de utensílios utilizados para o preparo de mamadeiras, provenientes de uma mesma Maternidade da cidade de Belo Horizonte, no Estado de Minas Gerais. 
Cronobacter spp.: infecções, ocorrência e regulação em alimentos - uma revisão no Brasil

Brandão, M. L. L. et al.

Tabela 2. Ocorrência de Cronobacter spp. em amostras de alimentos comercializados no Brasil.

\begin{tabular}{|c|c|c|c|}
\hline Amostra & N. ${ }^{\circ}$ positivo/total (\%) & Ano & Referência \\
\hline $\begin{array}{l}\text { Fórmula infantil para prematuros e recém-nascidos de } \\
\text { baixo peso }\end{array}$ & $3 / 14(21,4)$ & \multirow{6}{*}{2006} & \multirow{6}{*}{$\begin{array}{l}\text { Santos (2006), } \\
\text { Santos et al. (2013) }\end{array}$} \\
\hline Fórmula infantil (0-6 meses) & $3 / 45(6,7)$ & & \\
\hline Fórmula de seguimento (6-12 meses) & $8 / 33(24,2)$ & & \\
\hline Fórmula infantil (até 1 ano) & $0 / 6(0)$ & & \\
\hline Amido em pó & $4 / 7(57,1)$ & & \\
\hline Leite UHT integral & $0 / 3(0)$ & & \\
\hline Fórmula infantil (0-6 meses) & $0 / 4(0)$ & \multirow{5}{*}{2008} & \multirow{5}{*}{ Freitas et al. (2011) } \\
\hline Fórmula infantil (6-12 meses) & $0 / 7(0)$ & & \\
\hline Alimento infantil à base de farinha de milho (6-36 meses) & $4 / 8(50,0)$ & & \\
\hline $\begin{array}{l}\text { Alimento infantil à base de cereais de farinha de arroz } \\
\text { (6-36 meses) }\end{array}$ & $0 / 3(0)$ & & \\
\hline Aveia em flocos (6-36 meses) & $0 / 1(0)$ & & \\
\hline Fórmula infantil (0-6 meses) & $1 / 186(0,5)$ & 2008 & Palcich et al. (2009) \\
\hline Fórmula infantil (6-12 meses) & $0 / 31(0)$ & 2009 & Chap et al. (2009) \\
\hline Fórmulas lácteas em pó & $0 / 24(0)$ & 2011 & Oliveira et al. (2011) \\
\hline $\begin{array}{l}\text { Misturas de cereais para crianças com idade acima de } \\
\text { seis meses }\end{array}$ & $7 / 30(23,3)$ & \multirow{3}{*}{$\begin{array}{l}2013- \\
2014\end{array}$} & \multirow{3}{*}{ Brandao et al. (2017) } \\
\hline Temperos e condimentos & $11 / 30(36,7)$ & & \\
\hline Farinhas & $20 / 30(66,7)$ & & \\
\hline Alimento infantil à base de cereais variados & $1 / 16(6,3)$ & \multirow{6}{*}{2015} & \multirow{6}{*}{ Meier et al. (2016) } \\
\hline Alimento infantil à base de cereais de arroz & $6 / 11(54,5)$ & & \\
\hline Alimento infantil à base de cereais de milho & $1 / 9(11,1)$ & & \\
\hline Alimento infantil à base de cereais de aveia & $2 / 2(100,0)$ & & \\
\hline Farinha láctea & $1 / 4(25,0)$ & & \\
\hline Amido de milho & $0 / 5(0)$ & & \\
\hline Queijo Minas Frescal & $1 / 30(3,3)$ & \multirow{3}{*}{2015} & \multirow{3}{*}{ Brandao et al. (2016) } \\
\hline Queijo Prato & $0 / 30(0)$ & & \\
\hline Queijo Prato fatiado & $0 / 30(0)$ & & \\
\hline
\end{tabular}

\subsection{Regulamentação para o controle de Cronobacter spp. em fórmulas infantis desidratadas}

Cronobacter spp. foi classificado como "[...] microrganismos de risco severo para populações restritas, que representam ameaça à vida ou desenvolvimento de sequelas crônicas ou de longa duração [...]" (ICMSF, 2002, p. 68). Mesmo Cronobacter spp. podendo ser encontrado em uma série de produtos alimentícios, apenas FID foram epidemiologicamente identificadas como veículo de contaminação (CAC, 2008). A presença destes patógenos em FID levou ao recolhimento destes produtos por diferentes produtores, em diversos países, incluindo o Brasil (IBFAN, 2015).

Em 2006, o Codex Alimentarius, a FAO e a OMS promoveram uma reunião técnica para avaliação de dados científicos para aplicação de um modelo de análise de risco quantitativo para Cronobacter spp. em FID. Com base nessa avaliação, foi elaborado um manual sobre preparo, uso, manipulação e armazenamento de FID (FAO, 2007). Em 2008, foi publicada uma revisão do Código de Prática de Higiene para fórmulas em pó para lactantes de primeira infância do Codex Alimentarius, a qual, em seu Anexo I, preconiza a ausência de Cronobacter spp. em 30 amostras de unidades analíticas de $10 \mathrm{~g}$ para fórmulas infantis em pó para lactantes, fórmulas infantis em pó para lactantes com propósitos médicos especiais e fortificantes de leite humano (CAC, 2008). No Anexo II, que é referente a fórmulas de seguimento em pó e fórmulas para necessidades médicas especiais para crianças de 12 a 36 meses, não houve a inclusão de um critério para Cronobacter spp. Entretanto, foi incluído um adendo explicitando que, em países com substancial população de bebês até 12 meses com comprometimento imunológico, devem ser adotados para FIS os mesmos critérios para fórmulas infantis para lactantes (FIL) de zero a seis meses.

O critério determinado pelo documento do Codex Alimentarius (CAC, 2008) foi também adotado pelos países membros da União Europeia (EUROPEAN UNION, 2007). No Brasil, a RCD n. ${ }^{\circ} 12$ de 02/01/2001 (BRASIL, 2001), que é a resolução que estabelece os padrões microbiológicos para alimentos atualmente em vigor, não contempla o padrão de pesquisa de Cronobacter spp. 
em FID. A revisão da RDC n. ${ }^{\circ}$ 12/2001 é um dos assuntos prioritários da Agenda Regulatória Biênio 2015-2016 da Anvisa (BRASIL, 2015) e espera-se que o critério para Cronobacter spp. em FID seja contemplado nesta revisão.

Como a RDC n. ${ }^{\circ} 12 / 2001$ não foi revisada, a Anvisa tomou outras medidas para garantir a segurança da população quanto ao risco da contaminação por Cronobacter spp. em FID. Em 2011, foram publicadas as RDC n. ${ }^{\circ} 43,44$ e 45 , que estabelecem o regulamento técnico para fórmulas infantis para lactantes, para fórmulas infantis de seguimento para lactantes e crianças de primeira infância, para fórmulas infantis lactantes destinadas a necessidades dietoterápicas específicas e fórmulas infantis de seguimento para lactantes e crianças de primeira infância, destinadas a necessidades dietoterápicas específicas, respectivamente (BRASIL, 2011a,b,c). Nestas resoluções, foi adotado que os produtos devem cumprir o disposto no Codex Alimentarius (CAC, 2008) e suas atualizações, bem como as Diretrizes para preparação, armazenamento e manipulação, em condições higiênicas de preparações em pó para lactantes (FAO, 2007). Além disso, as resoluções supracitadas determinaram que os rótulos das fórmulas devessem conter instruções claras de que o produto deve ser preparado com água fervida e posteriormente resfriada à temperatura não inferior a $70{ }^{\circ} \mathrm{C}$, para produtos que necessitam reconstituição. Também existem instruções sobre a importância do consumo imediato da fórmula reconstituída e a informação de que, quando necessário o preparo com antecedência do produto, a fórmula reconstituída deve ser refrigerada a uma temperatura inferior a $5^{\circ} \mathrm{C}$ por, no máximo, 24 horas. A questão da reconstituição do produto nesta temperatura acabou levantando diversos questionamentos por parte do setor produtivo, como a possível perda de nutrientes termossensíveis; a eventual formação de grumos; o risco de queimaduras; a ativação de esporos de outras bactérias; a inviabilidade do uso de probióticos, e a dificuldade de se mensurar a temperatura em questão. Com isso, a Anvisa publicou o Informe Técnico n. ${ }^{\circ} 59$ de 2014 (BRASIL, 2014a), relativo à diluição de fórmulas infantis à temperatura de $70^{\circ} \mathrm{C}$ e ao risco de infecção por Cronobacter spp., explicitando os motivos que levaram à adoção destas medidas de segurança. Posteriormente, a fim de subsidiar e qualificar essa discussão, a Anvisa realizou uma consulta aos especialistas no tema e ao setor produtivo, a fim de esclarecer algumas questões importantes a respeito do risco de infecção por Cronobacter spp. de lactantes maiores de seis meses (BRASIL, 2014b).

\section{Conclusões}

Casos de infecções por Cronobacter em neonatos e adultos já foram reportados em duas Regiões do Brasil, no período de 1997 a 2013, com maior ocorrência em neonatos. O único estudo que identificou as cepas de origem clínica, em nível de espécie, relatou que as infecções foram causadas por cepas da espécie C. malonaticus. Determinados métodos fenotípicos, ainda utilizados em laboratórios clínicos no Brasil, podem não ser adequados para a correta identificação de Cronobacter, o que leva à subestimação da ocorrência dos casos de infecções que ocorrem no País. Cronobacter já foi isolada de amostras de fórmulas infantis, temperos e condimentos, farinhas, queijo e alimentos para crianças, sendo que quatro espécies foram identificadas: C. sakazakii, C. malonaticus, C. dublinensis e C. muytjensii. $O$ incentivo à realização de pesquisas sobre a epidemiologia do gênero Cronobacter é importante para identificar as classes de alimentos que podem atuar como veículo de contaminação, e a real prevalência das infecções no Brasil.

\section{Agradecimentos}

Ao Programa de Pós-Graduação em Vigilância Sanitária do INCQS/Fiocruz, no qual Marcelo Brandão foi doutorando. Ao CNPq, por concessão de Bolsa PIBIC a Natália Umeda.

\section{Referências}

BARREIRA, E. R.; SOUZA, E. R.; GOIS, D. C.; FREITAS, P. F.; FERNANDES, J. C. Meningite por Enterobacter sakazakii em recém-nascido: relato de caso. Pediatria, v. 25, n. 1/2, p. 65-70, 2003.

BHAT, G. K.; ANANDHI, R. S.; DHANYA, V. C.; SHENOY, S. M. Urinary tract infection due to Enterobacter sakazakii. Indian Journal of Pathology \& Microbiology, v. 52, n. 3, p. 430-431, 2009. PMid:19679984. http://dx.doi.org/10.4103/0377-4929.55017.

BOWEN, A. B.; BRADEN, C. R. Invasive Enterobacter sakazakii in infants. Emerging Infectious Diseases, v. 12, n. 8, p. 1185-1189, 2006. PMid:16965695. http://dx.doi.org/10.3201/eid1208.051509.

BRANDAO, M. L. L.; MEIER, G. O.; CARVALHO, C. R.; SILVA, D. A. F.; UMEDA, N. S.; MEDEIROS, V. M.; ROSAS, C. O.; LOPES, S. M. R. Identificação de Cronobacter spp. em queijos e perfil de suscetibilidade antimicrobiana. Revista do Instituto Adolfo Lutz, v. 75, p. 1697, 2016.

BRANDAO, M. L. L.; UMEDA, N. S.; CARVALHO, K. R.; FILIPPIS, I. Investigação de um surto causado por Cronobacter malonaticus em um hospital maternidade em Teresina, Piauí: caracterização e tipificação por eletroforese em gel de campo pulsado. Vigilância Sanitária em Debate, v. 3, n. 3, p. 91-96, 2015.

BRANDAO, M. L. L.; UMEDA, N. S.; JACKSON, E.; FORSYTHE, S. J.; FILIPPIS, I. Isolation. Molecular and phenotypic characterization, and antibiotic susceptibility of Cronobacter spp. from Brazilian retail foods. Food Microbiology, v. 63, p. 129-138, 2017. PMid:28040160. http://dx.doi.org/10.1016/j.fm.2016.11.011.

BRASIL. Agência Nacional de Vigilância Sanitária. Resolução RDC n. ${ }^{\circ} 12$, de 2 de janeiro de 2001. Aprova regulamento Técnico 
Cronobacter spp.: infecções, ocorrência e regulação em alimentos - uma revisão no Brasil

Brandão, M. L. L. et al.

sobre Padrões Microbiológicos para alimentos e seus anexos I e II. Diário Oficial [da] República Federativa do Brasil, Poder Executivo, Brasília, DF, n. 7-E, 2001. Seção 1, p. 45.

BRASIL. Agência Nacional de Vigilância Sanitária. Resolução RDC n. ${ }^{\circ} 43$ de 19 de setembro de 2011. Dispõe sobre o regulamento técnico para fórmulas infantis para lactantes. Diário Oficial [da] República Federativa do Brasil, Poder Executivo, Brasília, DF, n. 182, 21 set. 2011a. Seção 1. p. 90-92.

BRASIL. Agência Nacional de Vigilância Sanitária. Resolução RDC n. ${ }^{\circ} 44$ de 19 de setembro de 2011. Dispõe sobre o regulamento técnico para fórmulas infantis de seguimento para lactantes e crianças de primeira infância. Diário Oficial [da] República Federativa do Brasil, Poder Executivo, Brasília, DF, n. 182, 21 set. 2011 b. Seção 1, p. 92-94.

BRASIL. Agência Nacional de Vigilância Sanitária. Resolução RDC n. ${ }^{\circ} 45$ de 19 de setembro de 2011. Dispõe sobre o regulamento técnico para fórmulas infantis lactantes destinadas a necessidades dietoterápicas específicas e fórmulas infantis de seguimento para lactantes e crianças de primeira infância destinadas a necessidades dietoterápicas específicas. Diário Oficial [da] República Federativa do Brasil, Poder Executivo, Brasília, DF, n. 182, 21 set. 2011c. Seção 1, p. 94-96.

BRASIL. Agência Nacional de Vigilância Sanitária. Câmara Técnica de Alimentos - CAT. Diluição de fórmulas infantis a temperatura de $70^{\circ} \mathrm{C}$ e risco de infecção por Enterobacter sakazakii (Cronobacter spp.). Brasília: ANVISA, 2014a. 6 p. (Informe Técnico, n 59).

BRASIL. Agência Nacional de Vigilância Sanitária. Edital de Chamamento n. ${ }^{\circ}$ 2, de 29 de julho de 2014. Edital de Chamamento para coletar dados e informações a respeito do risco de infecções de lactantes maiores de seis meses por E. sakazakii (Cronobacter spp.). Diário Oficial [da] República Federativa do Brasil, Poder Executivo, Brasília, DF, n. 144, 30 jul. 2014b. Seção 3, p. 92-93.

BRASIL. Ministério da Saúde. Portaria n 1271, de 06 de junho de 2014. Define a lista nacional de notificação compulsória de doenças, agravos e eventos de saúde pública em todo o território nacional. Diário Oficial [da] República Federativa do Brasil, Poder Executivo, Brasília, DF, 9 jun. 2014c.

BRASIL. Ministério da Saúde. Doenças Transmitidas por Alimentos - Situação Epidemiológica - Dados Epidemiológicos - DTA 2010 a 2014. Brasília, 2014d. Disponível em: <http://foodsafetybrazil. org/surtos-alimentares-no-brasil-dados-atualizados-em-2014/>. Acesso em: 8 maio 2017.

BRASIL. Agência Nacional de Vigilância Sanitária. Regulação Sanitária. Agenda Regulatória Biênio 2015-2016. Ciclo Quadrienal - Agenda Regulatória Biênio 2015-2016. Brasília: ANVISA, 2015.

CHAP, J.; JACKSON, P.; SIQUEIRA, R.; GASPAR, N.; QUINTAS, C.; PARK, J.; OSAILI, T.; SHAKER, R.; JARADAT, Z.; HARTANTYO, S. H.; ABDULLAH SANI, N.; ESTUNINGSIH, S.; FORSYTHE, S. J. International survey of Cronobacter sakazakii and other
Cronobacter spp. in follow up formulas and infant foods. International Journal of Food Microbiology, v. 136, n. 2, p. 185-188, 2009. PMid:19729216. http://dx.doi.org/10.1016/j. ijfoodmicro.2009.08.005

CODEX ALIMENTARIUS COMISSION - CAC. Codex Alimentarius: code of hygienic practice for foods for powdered formulae for infants and young children. Washington: CAC/RCP 66, 2008.

EUROPEAN UNION. Commission Regulation - EC. The commissions of the European communities, Commission Regulation (EC) $n^{\circ}$ 1441/2007 of 5 December 2007 amending Commission Regulation (EC) $n^{\circ} 2073 / 2005$ on microbiological criteria for foodstuffs. Official Journal of the European Union, L322, 2007. p. 12-29.

FARMER 3RD, J. J.; ASBURY, M. A.; HICKMAN, F. W.; BRENNER, D. J. The Enterobacteriaceae Study Group (USA). Enterobacter sakazakii: a new species of Enterobacteriaceae isolated from clinical species. International Journal of Systematic and Evolutionary Microbiology, v. 30, n. 3, p. 569-584, 1980.

FARMER 3RD, J. J. My 40-year history with Cronobacterl Enterobacter sakazakii-lessons learned, myths debunked, and recommendations. Frontiers in Pediatrics, v. 3, n. 84, p. 84, 2015. PMid:26640778. http://dx.doi.org/10.3389/fped.2015.00084.

FOOD AND AGRICULTURAL ORGANIZATION - FAO; WORLD HEALTH ORGANIZATION - WHO. Safe preparation, storage and handling of powdered infant formula: guidelines. Genova: WHO, 2007. $26 \mathrm{p}$

FOOD AND AGRICULTURAL ORGANIZATION - FAO; WORLD HEALTH ORGANIZATION - WHO. Enterobacter sakazakii (Cronobacter spp.) in powdered follow-up formulae: meeting report. Genova: WHO, 2008. 90 p. (Microbiological Risk Assessment Series, 15).

FORSYTHE, S. J.; DICKINS, B.; JOLLEY, K. A. Cronobacter, the emergent bacterial pathogen Enterobacter sakazakii comes of age; MLST and whole genome sequence analysis. BMC Genomics, v. 15, n. 1, p. 1121, 2014. PMid:25515150. http:// dx.doi.org/10.1186/1471-2164-15-1121.

FREITAS, L. G.; RISTORI, C. A.; JAKABI, M.; PAULA, A. M. R.; ROWLANDS, R. E. G. Ocorrência de Cronobacter spp. (Enterobacter sakazakii) em alimentos infantis adquiridos em um hospital público. Revista do Instituto Adolfo Lutz, v. 70, n. 4, p. 548-553, 2011.

FRIEDEMANN, M. Epidemiological of invasive neonatal Cronobacter (Enterobacter sakazakii) infections. European Journal of Clinical Microbiology \& Infectious Diseases, v. 28, n. 11, p. 1297-1304, 2009. PMid:19662446. http://dx.doi.org/10.1007/ s10096-009-0779-4.

HARIRI, S.; JOSEPH, S.; FORSYTHE, S. J. Cronobacter sakazakii ST4 Strains and Neonatal Meningitis, United States. Emerging Infectious Diseases, v. 19, n. 1, p. 175-177, 2013. PMid:23260316. http://dx.doi.org/10.3201/eid1901.120649. 
Cronobacter spp.: infecções, ocorrência e regulação em alimentos - uma revisão no Brasil

Brandão, M. L. L. et al.

INTERNATIONAL BABY FOOD ACTION NETWORK - IBFAN. Reports and briefings on Contaminants in Baby Foods (and Product Recall List). Penang: ICDC/IBFAN International Code Documentation Centre, 2015. Disponível em: <http://ibfan.org/ fact-contaminants-reports-recall>. Acesso em: 8 maio 2017.

INTERNATIONAL COMISSION FOR MICROBIOLOGICAL SPECIFICATIONS FOR FOODS - ICMSF. Microorganisms in foods 7: microbiological testing in food safety management. New York: Kluwer Academic/Plenum Publishers, 2002.

IVERSEN, C.; LEHNER, A.; MULLANE, N.; BIDLAS, E.; CLEENWERCK, I.; MARUGG, J.; FANNING, S.; STEPHAN, R.; JOOSTEN, H. The taxonomy of Enterobacter sakazakii: proposal of a new genus Cronobacter gen. nov. and descriptions of Cronobacter sakazakii comb. nov. Cronobacter sakazakii subsp. sakazakii, comb. nov., Cronobacter sakazakii subsp. malonaticus subsp. nov., Cronobacter turicensis sp. nov., Cronobacter muytjensii sp. nov., Cronobacter dublinensis sp. nov. and Cronobacter genomospecies 1. BMC Evolutionary Biology, v. 7, n. 1, p. 64, 2007a.

IVERSEN, C.; LEHNER, A.; MULLANE, N.; MARUGG, J.; FANNING, S.; STEPHAN, R.; JOOSTEN, H. The identification of "Cronobacter spp." (Enterobacter sakazakii). Journal of Clinical Microbiology, v. 45, n. 11, p. 3814-3816, 2007b. PMid:17881547. http://dx. doi. org/10.1128/JCM.01026-07

IVERSEN, C.; MULLANE, N.; MCCARDELL, B.; TALL, B. D.; LEHNER, A.; FANNING, S.; STEPHAN, R.; JOOSTEN, H. Cronobacter gen. nov., a new genus to accommodate the biogroups of Enterobacter sakazakii, and proposal of Cronobacter sakazakii gen. nov., comb. nov., Cronobacter malonaticus sp. nov., Cronobacter turicensis sp. nov., Cronobacter muytjensii sp. nov., Cronobacter dublinensis sp. nov., Cronobacter genomospecies 1, and of three subspecies, Cronobacter dublinensis subsp. dublinensis subsp. nov., Cronobacter dublinensis subsp. lausannensis subsp. nov. and Cronobacter dublinensis subsp. lactaridi. subsp. nov. International Journal of Systematic and Evolutionary Microbiology, v. 58, n. Pt6, p. 1442-1447, 2008. PMID: 18523192. http://dx.doi.org/10.1099/ijs.0.65577-0.

JASON, J. Prevention of invasive cronobacter infections in young infants fed powdered infant formulas. Pediatrics, v. 130, n. 5, p. 1076-1084, 2012. PMid:23045556. http://dx.doi.org/10.1542/ peds.2011-3855.

JOSEPH, S.; CETINKAYA, E.; DRAHOVSKA, H.; LEVICAN, A.; FIGUERAS, M. J.; FORSYTHE, S. J. Cronobacter condimentisp. nov., isolated from spiced meat and Cronobacter universalis sp. nov., a novel species designation for Cronobacter sp. genomospecies 1, recovered from leg infection, water, and food ingredients. International Journal of Systematic and Evolutionary Microbiology, v. 62, n. Pt6, p. 1277-1283, 2012.

JOSEPH, S.; FORSYTHE, S. J. Predominance of Cronobacter sakazakii Sequence Type 4 in Neonatal Infections. Emerging Infectious Diseases, v. 17, n. 9, p. 1713-1715, 2011. PMid:21888801. http://dx.doi.org/10.3201/eid1709.110260.
JOSEPH, S.; HARIRI, S.; FORSYTHE, S. J. Lack of continuity between Cronobacter biotypes and species as determined using multilocus sequence typing. Molecular and Cellular Probes, v. 27, n. 3-4, p. 137-139, 2013. PMid:23474194. http://dx.doi. org/10.1016/j.mcp.2013.02.002.

LAI, K. K. Enterobacter sakazakii infections among neonates, infants, children and adults: case reports and a review of the literature. Medicine, v. 80, n. 2, p. 113-122, 2001. PMid:11307587. http://dx.doi.org/10.1097/00005792-200103000-00004.

MEIER, G. O.; BRANDAO, M. L. L.; MEDEIROS, V. M.; ROSAS, C. O.; SILVA, D. A. F.; CARVALHO, C. R.; SILVA, C. C.; UMEDA, N. S.; LOPES, S. M. Pesquisa, identificação e perfil de suscetibilidade antimicrobiana de Cronobacter spp. em produtos destinados à alimentação infantil. Revista do Instituto Adolfo Lutz, v. 75, p. 1690, 2016.

OLIVEIRA, A. C.; MARTINHO, G. H.; DIAS, R. R.; SAVASSI, L. C. M. Investigação de surto por Enterobacter sakazakii na Unidade de Neonatologia do HC/UFMG. In: BIENAL DE EXTENSÃO DA UNIVERSIDADE FEDERAL DE MINAS GERAIS, 2., 1999, Belo Horizonte. Anais... Belo Horizonte: UFMG, 1999. p. 103.

OLIVEIRA, J. V.; SILVA, M. C. C.; LIMA, D. P.; AMÂNCIO, G. C. S.; VASCONCELOS NETO, M. C. Avaliação da Incidência de Cronobacter spp. em Maternidades Públicas de Belo Horizonte-MG. In: CONGRESSO BRASILEIRO DE MICROBIOLOGIA, 26., 2011, Foz do Iguaçu, Paraná. Anais... Foz do Iguaçu: SBM, 2011. Resumo 108-1.

PALCICH, G.; GILLIO, C. M.; ARAGON-ALEGRO, L. C.; PAGOTTO, F. J.; FARBER, J. M.; LANDGRAF, M.; DESTRO, M. T. Enterobacter sakazakii in dried infant formulas and milk kitchens of maternity wards in São Paulo, Brazil. Journal of Food Protection, v. 72, n. 1, p. 37-42, 2009. PMid:19205461. http://dx.doi.org/10.4315/0362028X-72.1.37.

PATRICK, M. E.; MAHON, B. E.; GREENE, S. A.; ROUNDS, J.; CRONQUIST, A.; WYMORE, K.; BOOTHE, E.; LATHROP, S.; PALMER, A.; BOWEN, A. Incidence of Cronobacter spp. infections, United States, 2003-2009. Emerging Infectious Diseases, V. 20, n. 9, p. 1520-1523, 2014.

RAY, P.; DAS, A.; GAUTAM, V.; JAIN, N.; NARANG, A.; SHARMA, M. Enterobacter sakazakii in infants: novel phenomenon in India. Indian Journal of Medical Microbiology, v. 25, n. 4, p. 408-410, 2007. PMid:18087097. http://dx.doi.org/10.4103/0255-0857.37351.

SANTOS, M.; SILVA, C. L. P.; SAMPAIO, J.; MARANGONI, D. V.; PINTO, M.; MOREIRA, B. M. Detection and control of Enterobacter sakazakii sepsis outbreak in four hospitals in Rio de Janeiro, Brazil. Infection Control and Hospital Epidemiology, v. 21, n. 2, p. 140, 2000.

SANTOS, R. F. S. Ocorrência de Enterobacter sakazakii em fórmulas infantis para lactentes em hospitais e maternidades da região de Campinas/SP. 2006. 91 f. Dissertação (Mestrado) - Faculdade de Engenharia de Alimentos, Universidade Estadual de Campinas, Campinas, 2006. 
Cronobacter spp.: infecções, ocorrência e regulação em alimentos - uma revisão no Brasil

Brandão, M. L. L. et al.

SANTOS, R. F. S.; SILVA, N.; JUNQUEIRA, V. C. A.; KAJSIK, M.; FORSYTHE, S. J.; PEREIRA, J. L. Screening for Cronobacter species in powdered and reconstituted infant formulas and from equipment used in formula preparation in maternity hospitals. Annals of Nutrition \& Metabolism, v. 63, n. 1-2, p. 62-68, 2013. PMid:23941974. http://dx.doi.org/10.1159/000353137.

SEE, K. C.; THAN, H. A.; TANG, T. Enterobacter sakazakii bacteraemia with multiple splenic abscesses in a 75-year-old woman: a case report. Age and Ageing, v. 36, n. 5, p. 595-596, 2007. PMid:17646217. http://dx.doi.org/10.1093/ ageing/afm092.

STRYDOM, A.; CAWTHORN, D.; CAMERON, M.; WITTHUHN, R. C. Species of Cronobacter-a review of recent advances in the genus and their significance in infant formula milk. International Dairy Journal, v. 27, n. 1-2, p. 3-12, 2012. http://dx.doi.org/10.1016/j. idairyj.2012.06.005.

TSAI, H. Y.; LIAO, C. H.; HUANG, Y. T.; LEE, P. I.; HSUEH, P. R. Cronobacter infections not from Infant Formula, Taiwan. Emerging Infectious Diseases, v. 19, n. 1, p. 167-169, 2013. PMid:23260041. http://dx.doi.org/10.3201/eid1901.120774.

WARNKEN, M. B.; BRANDAO, M. L. L.; SOUZA, A. E.; ROMÃO, C. M. C. P.; NOGUEIRA, A. C. M. A.; DESTRO, M. T. Phenotypic profiles and detection of target genes by PCR in isolates from different sources and reference strains, identified as Cronobacter spp. (Enterobacter sakazakii). Revista do Instituto Adolfo Lutz, v. 71, n. 1, p. 21-23, 2012. 